\title{
Comparison of the Effects of Ionization Mechanism, Analyte Concentration, and Ion "Cool-Times" on the Internal Energies of Peptide Ions Produced by Electrospray and Atmospheric Pressure Matrix-Assisted Laser Desorption Ionization
}

\author{
David O. Konn, Jason Murrell, and Dominique Despeyroux \\ Dstl, Detection Department, Porton Down, Wiltshire, United Kingdom
}

\author{
Simon J. Gaskell \\ Michael Barber Center for Mass Spectrometry, School of Chemistry, University of Manchster, Manchester, \\ United Kingdom
}

\begin{abstract}
The propensities of a series of peptide ions produced by both electrospray and atmospheric pressure matrix assisted laser desorption ionization (AP-MALDI) to fragment in an ion trap mass spectrometer under various conditions were studied in detail by measuring the extent of fragmentation of precursor ions by collision induced dissociation (CID) as a function of applied resonance excitation RF voltage. For the most basic peptides, the energy required to fragment $\mathrm{MH}^{+}$ions generated by electrospray exceeded that required to fragment equivalent AP-MALDI ions under identical instrumental conditions; the reverse was observed for a peptide incorporating no basic residues, while peptides of intermediate basicity showed little difference between the ionization methods. This correlation between peptide basicity and the difference in the energy required to induce fragmentation of $\mathrm{MH}^{+}$ions generated by AP-MALDI and electrospray is attributed primarily to a trend in the internal energies of the ions generated by AP-MALDI (the greater the difference in gas-phase basicities between the matrix and the analyte the greater the internal energy of the analyte ions produced). Furthermore the internal energies of ions produced by AP-MALDI, but not the equivalent ions formed by electrospray, were observed to decrease with decreasing analyte concentration. We attribute this finding to the cooling effect of endothermic dissociation of analyte ion/matrix molecule clusters following the matrix assisted laser desorption step. Time-resolved analyses (measurement of extent of fragmentation of precursor ions by CID as a function of pre-CID "cool times") revealed that cooling periods in excess of $250 \mathrm{~ms}$ were required to achieve internal energy equilibrium through cooling collisions with the helium buffer gas. Furthermore, these analyses demonstrated that, even after these extended cooling times, equivalent ions formed by the two ionization techniques showed different propensities to fragment. We conclude that the two different ionization techniques produce ion populations that may differ in their three-dimensional structure. (J Am Soc Mass Spectrom 2005, 16, 743-751) (c) 2005 American Society for Mass Spectrometry
\end{abstract}

$\mathrm{T}$ The initial internal energy of an ion is determined by the internal energy of the analyte molecule before ionization and the energy deposited during ionization. The additional internal energy that must be acquired during ion activation in order for dissociation to occur is defined by the initial internal energy of

Published online March 11, 2005

Address reprint requests to Dr. D. Konn, Dstl, Detection Department, Porton Down, Salisbury, Wiltshire SP4 0JQ, United Kingdom. E-mail: dokonn@dstl.gov.uk the ion. Thus, for a fixed activation energy the extent of ion decomposition is a measure of the initial internal energy of that ion. Therefore, in order to compare the initial internal energies of peptide ions produced by electrospray and AP-MALDI, a series of energyresolved tandem mass spectrometry experiments were performed, in which the extent of decomposition of precursor ions by CID was measured as a function of applied resonance excitation RF voltage.

Danell and Glish [1] and Wysocki and coworkers [2] investigated the differences between the internal ener- 
gies of $\mathrm{MH}^{+}$ions of leucine-enkephalin generated by liquid secondary ion mass spectrometry (LSIMS) and nanoflow electrospray by boundary activated dissociation, and LSIMS and electrospray by surface induced dissociation, respectively, and both observed differences in the internal energies of ions generated by the two ionization techniques. After additional experiments to fix the position of the charge on the peptide and some time-resolved studies showing that the ions formed by the two techniques would not adopt the same energy distributions, Glish and coworkers were able to attribute this to different ion populations being produced by the different ionization techniques. Wysocki and coworkers suggested that a combination of the $\mathrm{MH}^{+}$ ions formed by electrospray being internally colder than those produced by LSIMS and differences in the relative populations of the various possible protonated forms of the molecular ion produced accounted for the observed difference in internal energies of the ion populations produced by the two techniques.

The design of both the electrospray and the APMALDI sources used in this study are such that switching between the two sources on the same instrument is possible without any alterations to the mass spectrometer or lensing system. This allows for the direct comparison of electrospray and AP-MALDI ions generated from the same sample and analyzed on the same instrument under otherwise identical instrumental conditions.

No detailed comparison has previously been drawn between the internal energy of ions formed by electrospray and AP-MALDI. A comparison of this nature would be of great interest because over the years a large knowledge base of electrospray ion trap tandem mass spectrometric data has been built up. It would therefore be useful to know if the typical fragmentations observed with electrospray generated ions in an ion trap mass spectrometer are also seen with AP-MALDI generated ions.

The same techniques were also used to examine the effect of analyte concentration on the internal energies of analyte ions resulting from both the AP-MALDI and the electrospray process, as it has been suggested that for techniques involving matrix assisted ionization there may be a correlation between analyte concentration and the internal energy of the analyte ions formed. In 1983, Cooks and Busch [3] noted a systematic increase in the abundance ratio of precursor ion to product ions with decreasing analyte concentration during secondary ion mass spectrometric analyses of organic compounds in an ammonium chloride matrix. The effect was attributed to the cooling effect of dissociation of [analyte ion/matrix neutral] complexes following the initial desorption step.

The lesser decomposition of steroid glucuronide $\mathrm{MH}^{+}$ions generated by fast atom bombardment of more dilute solutions in glycerol matrix, observed by Cole et al. [4], was similarly attributed to the endothermic dissociation of desorbed complexes. It is known that during the MALDI process clusters of matrix and analyte species are ablated into the gas phase [3,5-10]. These clusters are held together by hydrogen bonding and coulombic interactions [5] and the post-desorption loss of matrix neutrals from the clusters has been postulated to reduce the internal energies of the analyte ions released $[3,5,10]$. These suggestions have been substantiated by molecular dynamics calculations of the internal energies of analyte ions in laser-desorbed clusters, showing a decrease associated with progressive evaporation of matrix molecules [10].

Additionally, the effect of the "cooling time" on the internal energies of the analyte ions prior to undergoing CID was investigated via a series of time-resolved (measurement of extent of fragmentation of precursor ions by CID as a function of pre-CID cool times) tandem mass spectrometry experiments. The "cooling time" is defined as the time during which no supplemental RF voltages are applied to the endcap electrodes, and the amplitude of the RF on the ring electrode is sufficient to trap the ions of interest but not large enough to cause them to become excited. The effect of this "cooling time" on the internal energy of ions trapped in the ion trap is dependant on several factors including the nature of the ion itself (mass to charge ratio and number of degrees of freedom), the nature and pressure of the buffer gas, and the length of the "cooling period".

During the "cooling period", a number of processes occur that lead to a reduction in the internal energy of the trapped ions. Initially, the ion's kinetic energy is quenched through collisions with the buffer gas. At a helium buffer gas pressure of a mTorr an ion will experience, on average, 20 collisions with helium atoms every millisecond [11]. Much of the quenched kinetic energy is redistributed as internal energy within the ion, thus the internal energy of the ion rises initially. Quenching of internal energy (mainly vibrational) is much less efficient (by a factor of $\sim 10^{2}$ ) and occurs, therefore, over longer time-scales [11].

\section{Experimental}

\section{Mass Spectrometry}

All experiments were performed on an LCQ "DECA" ion trap mass spectrometer (ThermoFinnigan, San Jose, CA) equipped with an off-axis electrospray source (ThermoFinnigan) and an atmospheric pressure matrixassisted laser desorption ionization (AP-MALDI) source (Mass Technologies, Burtonsville, MD).

The following conditions were used for all energy and time-resolved experiments (electrospray and APMALDI): the electrospray needle/AP-MALDI target was held at $2.5 \mathrm{kV}$, the heated capillary was set at 200 ${ }^{\circ} \mathrm{C}$, and the flow rates of the nebulizing and auxiliary gases were approximately $0.6 \mathrm{l} / \mathrm{min}$ and $4.5 \mathrm{l} / \mathrm{min}$ (or 20 and 7 LCQ arbitrary units), respectively. The first multipole was offset by $-6.8 \mathrm{~V}$, the intermultipole lens was set at $-34 \mathrm{~V}$ and the second multipole offset by 
$-10 \mathrm{~V}$. The entrance lens was set at $-73 \mathrm{~V}$. The automatic $^{\circ}$ gain $^{\circ} \operatorname{control}^{\circ}\left(\mathrm{AGC}^{\circ}[12]^{\circ}\right.$ was $^{\circ}$ turned ${ }^{\circ}$ off ${ }^{\circ}$ and the ion injection time was set to $400 \mathrm{~ms}$.

The extended ion injection period allows a valid comparison to be made between the ion populations generated by the two methods, as it allows similar ion currents to be achieved in the two experiments. The typical ion injection times set by the AGC, which is designed for use with a continuous (electrospray) source, are of the order of several milliseconds and, when used in conjunction with the pulsed (AP-MALDI) source, did not allow sufficient ions into the ion trap to generate ion currents equivalent to those produced by electrospray ionization. In order to achieve equivalent ion currents it was necessary to turn the AGC off and set the ion injection time manually to a value of the order of several hundred milliseconds. The reason is that, by injecting ions for this length of time, the ion trap becomes filled too close to the storage space charge limit (for the particular ion being accumulated) and hence contains a similar number of ions from both ionization techniques. Having similar numbers of ions in the ion trap from both ionization techniques and accumulating them over the same period of time is important in order to try to standardize any factors that may affect the internal energies of the ions post-ionization. These factors include differences in space charge effects and any collisional cooling that may occur through collisions with the helium buffer gas during the ion injection period.

For the coanalysis of pairs of peptides experiments, the electrospray needle was held at $5 \mathrm{kV}$, the heated capillary was set to $300{ }^{\circ} \mathrm{C}$ and the flow rates of the nebulizing and auxiliary gases were approximately $1.7 \mathrm{l} / \mathrm{min}$ and $9.2 \mathrm{l} / \mathrm{min}$ (or 60 and 40 LCQ arbitrary units), respectively. The first multipole was offset by $-6.8 \mathrm{~V}$, the intermultipole lens was set at $-34 \mathrm{~V}$, and the second multipole offset by $-10 \mathrm{~V}$. The entrance lens was ${ }^{\circ}$ set $^{\circ} \mathrm{at}^{\circ}-73^{\circ} \mathrm{V}$. ${ }^{\circ}$ The $^{\circ} \mathrm{AGC}^{\circ}$ was ${ }^{\circ}$ turned ${ }^{\circ}$ on $^{\circ}$ and ${ }^{\circ}$ set $^{\circ}$ to ${ }^{\circ} 5$ $\times 10^{7}$.

The scan function used to perform the energyresolved ${ }^{\circ} \mathrm{MS} / \mathrm{MS}^{\circ}$ experiments $^{\circ}\left(\text { Figure }^{\circ} 1\right)^{\circ}$ incorporates several delay or "cooling" periods, during which no supplemental RF voltages are applied to the endcap electrodes, and the amplitude of the RF on the ring electrode is sufficient to trap the ions of interest in the ion trap but not large enough to cause them to be excited. There is one of these "cooling" periods before the isolation ${ }^{\circ}$ period $\%$ asting ${ }^{\circ} 10^{\circ} \mathrm{ms}^{\circ}$ (period $2^{\circ}{ }^{\circ}{ }^{\circ}$ Figure 1 ), another before the fragmentation period lasting $6 \mathrm{~ms}$ (period ${ }^{\circ} 4^{\circ}$ in $^{\circ}$ Figure $\left.^{\circ} 1\right)^{\circ}$ and $^{\circ} a^{\circ}$ third ${ }^{\circ}$ before ${ }^{\circ}$ the ${ }^{\circ}$ analytical scan $^{\circ}$ of $^{\circ} 6^{\circ} \mathrm{ms}^{\circ}\left(\right.$ period $^{\circ} 6^{\circ}{ }^{\circ}{ }^{\circ}$ Figure $\left.^{\circ} 1\right)$.

Customised waveforms allowing the length of the "cooling" "period before"fragmentation"(period 4 in 'Figure 1) ${ }^{\circ} \mathrm{at}^{\circ} \mathrm{q}_{\mathrm{z}} 0.25$ to be varied were generated on an Odyssey data system and the associated arbitrary waveform generator electronics from a Fourier-transform MS (ThermoFinnigan, Bremen, Germany) and replaced the waveforms produced by the LCQ "DECA" on-board wavecard $^{\circ}\left(\right.$ Figure $\left.^{\circ} 2\right) .^{\circ}$ The $^{\circ}$ external $^{\circ}$ waveforms, $^{\circ}$ once generated were stored on the Odyssey system until they were automatically triggered by a transistor-transistor logic (TTL) signal produced on pin TP15-3_Sync TP of the main power board of the LCQ "DECA" that coincides with the start of the analytical scan (J. C. Schwartz, personal communication, 1996). This TTL signal from pin TP15-3_Sync TP was input to pin 5 of the Odyssey data system I/O array. As all the post isolation waveforms normally produced by the LCQ "DECA" were disconnected, the RF waveform at $348 \mathrm{kHz}$ used for axial modulation was also supplied by the Odyssey data system. The axial modulation waveform produced on the Odyssey data system differed from that generated by the LCQ "DECA" as the amplitude of the waveform applied was set at a constant value during the acquisition phase and was not ramped as is the standard method.

\section{Materials}

Leucine-enkephalin and des-Arg ${ }^{1}$ bradykinin were purchased from Sigma (Poole, Dorset, UK) and used without further purification. Synthetic peptides AFLDASK, AFLDASR, and IGDYAGIK were purchased from SigmaGenosys (Pampisford, Cambridge, UK) and used without further purification. $\alpha$-cyano-4-hydroxycinnamic acid (HCCA) from Sigma was used as the AP-MALDI matrix.

\section{Sample Preparation}

Electrospray analyses: all samples were made up to $1 \mathrm{pmol} / \mu \mathrm{l}$ (unless otherwise stated) in methanol:water (1:1 vol/vol) with $0.1 \%$ formic acid, and infused into the mass spectrometer at a flow rate of $3 \mu \mathrm{l} / \mathrm{min}$. For comparisons of gas-phase basicity by coanalysis of two peptides, solutions of the analytes were prepared to 2.5 $\mathrm{pmol} / \mu \mathrm{l}$ for each component.

AP-MALDI samples: targets were prepared by the "dried droplet" method as follows: a $0.75 \mu \mathrm{l}$ volume of a $1 \mathrm{pmol} / \mu \mathrm{l}$ solution (unless otherwise stated) of the peptide (in 1:1 vol/vol methanol:water with $0.1 \%$ formic acid) was spotted onto the target. This was immediately followed by the addition of an equal volume of matrix solution (saturated solution of HCCA in 100\% methanol). The mixture was then left to dry on the open bench, before being analyzed immediately.

\section{Results and Discussion}

\section{Effect of Ionization Mechanism on Internal Energy}

Table 1 shows the applied ${ }^{\circ}$ resonance excitation $\mathrm{RF}^{\circ}$ voltage (peak-to-peak) necessary to achieve $50 \%$ fragmentation for des-Arg ${ }^{1}$ bradykinin, AFLDASR, AFLDASK, IGDYAGIK, and leucine-enkephalin, generated by both electrospray and $^{\circ}$ AP-MALDI. ${ }^{\circ}$ Figure $^{\circ} 3^{\circ}$ shows $^{\circ}$ this ${ }^{\circ}$ graphically ${ }^{\circ}$ with plots of the extents of fragmentation as a function of applied resonance excitation $\mathrm{RF}$ voltage for the $\mathrm{MH}^{+}$ion of this series of peptides generated by electrospray and by 


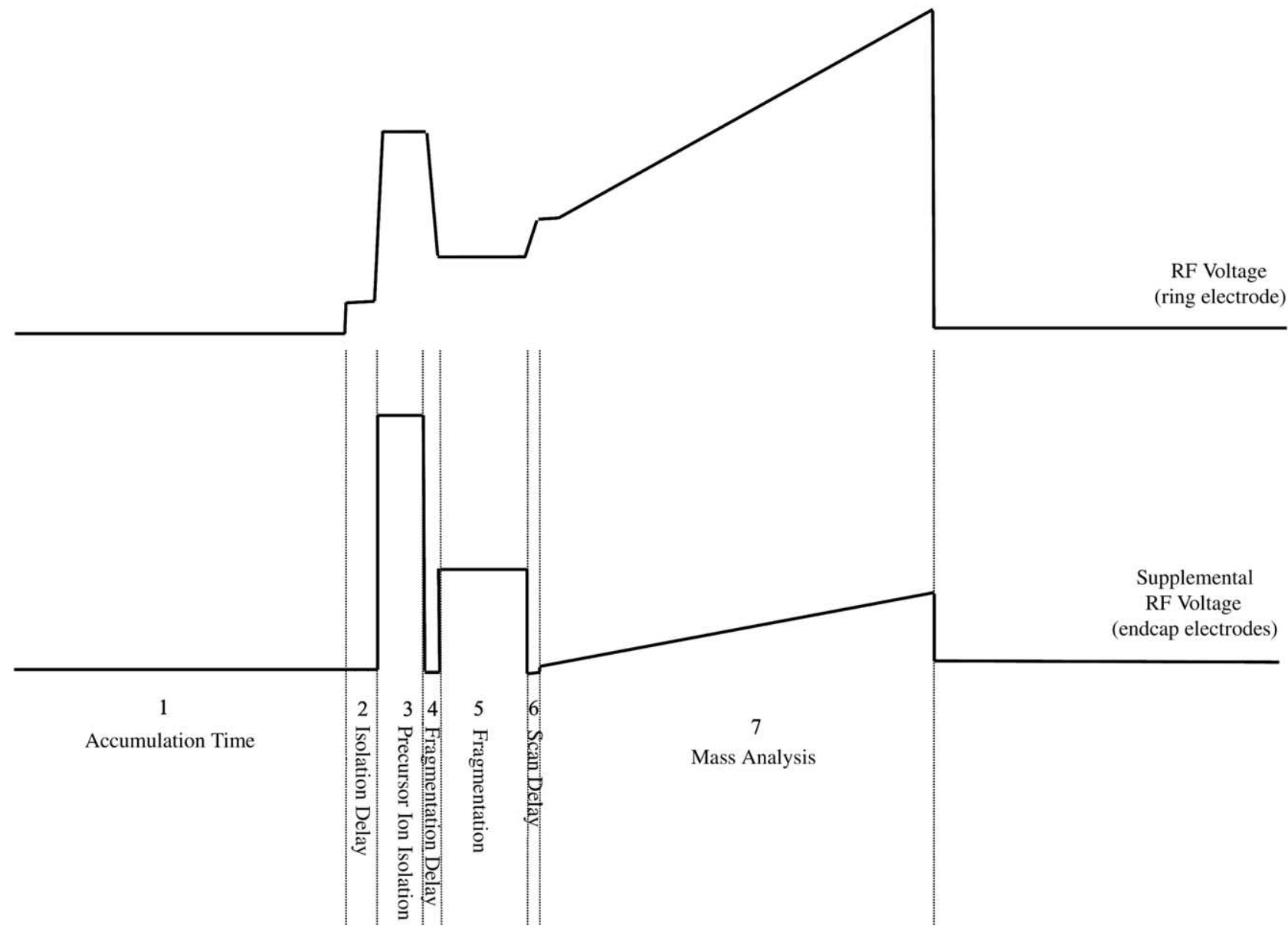

Figure 1. Schematic of MS/MS scan function used in both energy-resolved and time-resolved experiments.

AP-MALDI. Experimental conditions (electrospray needle/MALDI plate voltages, lens voltages, etc.), other than applied excitation voltage, were identical for all energyresolved CID analyses.

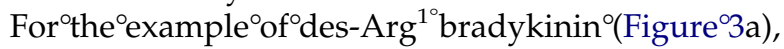
a significant displacement between the curves fitted to the two sets of data is apparent (and is reproducible, as judged by repeat analyses on separate days; data not shown). Thus, to achieve $50 \%$ fragmentation of the precursor, an applied resonance excitation RF voltage (peak-to-peak) of $0.94 \mathrm{~V}$ must be applied to AP-MALDI generated ions, compared with $1.02 \mathrm{~V}$ for the corresponding electrosprayed ions (an $8.2 \%$ difference). These data suggest that the ions generated by APMALDI for this peptide have a higher internal energy (requiring the addition of less excitation energy in order to cause them to fragment) than the corresponding ions generated by electrospray.

Figures $^{\circ} 3 \mathrm{~b}-\mathrm{d}^{\circ}$ show $^{\circ}$ energy-resolved ${ }^{\circ}$ data $^{\circ}$ for ${ }^{\circ}$ the peptides AFLDASR, AFLDASK, and IGDYAGIK respectively. For these examples, little difference was observed between corresponding fragmentation efficiency curves obtained for the $\mathrm{MH}^{+}$ions generated by electrospray and AP-MALDI.
Figure $^{\circ} 3 \mathrm{e}^{\circ}$ shows $^{\circ}$ energy-resolved $^{\circ}$ data $^{\circ}$ for ${ }^{\circ}$ leucineenkephalin $\mathrm{MH}^{+}$ions generated by electrospray and by AP-MALDI. It appears that, in this case, the ions generated by electrospray have a higher internal energy than those generated by AP-MALDI. Electrospray generated ions require an applied resonance excitation RF voltage (peak-to-peak) of $0.73 \mathrm{~V}$ to achieve $50 \%$ fragmentation, while AP-MALDI produced ions exhibit $50 \%$ fragmentation with the application of $0.79 \mathrm{~V}$ (a $7.9 \%$ difference). Additional evidence for a difference in ion internal energy associated with the ionization technique comes from plots of the abundance ratio of the $\mathrm{b}_{3} / \mathrm{y}_{2}$ first generation product ions of leucine-enkephalin as a function of applied resonance excitation voltage (Figure $\left.^{\circ} 4\right)^{\circ} .^{\circ}$ At $^{\circ}$ identical $^{\circ}$ applied $^{\circ}$ resonance $^{\circ}$ excitation voltages the ratio is greater for the ions generated by electrospray than those produced by AP-MALDI. The intensity ratio for the $b_{3}$ and $y_{2}$ products $(\mathrm{m} / \mathrm{z} 278$ and 279 , respectively) has been studied previously and suggested to be a reliable index of internal energy, where a higher ratio has been taken to indicate a higher internal'energy $[13,14]$. Equivalent ${ }^{\circ}$ plots ${ }^{\circ}$ were prepared (data not shown) for the relationship between the abundance ratio of the $a_{4} / b_{4}$ first generation product 


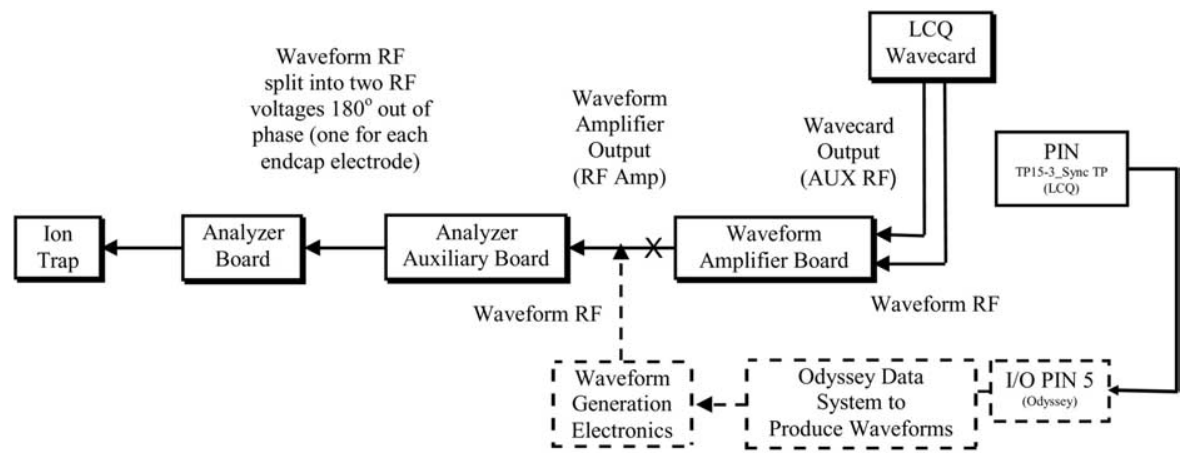

Figure 2. Schematic describing the interfacing of the Odyssey data system and associated electronics to the LCQ "DECA."

ions of leucine-enkephalin, which has also been proposed as an indicator of precursor ion internal energy $\left[15,{ }^{\circ} 16\right]{ }^{\circ}{ }^{\top}$ This ${ }^{\circ}$ ratio $^{\circ}$ was $^{\circ}$ again ${ }^{\circ}$ uniformly ${ }^{\circ}$ higher ${ }^{\circ}$ for ${ }^{\circ}$ ions generated by electrospray. This is in agreement with the energy-resolved CID data for leucine-enkephalin which consistently indicate a higher internal energy for $\mathrm{MH}^{+}$ ions generated by electrospray than by AP-MALDI, when experimental conditions were identical in all respects other than applied excitation voltage.

In order to facilitate interpretation of these data, the gas-phase basicities of the peptides used were ranked by application of the kinetic method first introduced by Cooks $^{\circ}$ and ${ }^{\circ}$ coworkers $^{\circ}[17] .{ }^{\circ}$ Thus, ${ }^{\circ}$ pairs ${ }^{\circ}$ of ${ }^{\circ}$ peptides ${ }^{\circ}$ were coanalyzed by electrospray at high concentrations. The proton-bound heterodimers so formed were selected and subjected to CID, and the relative abundances of the protonated monomers were determined. The determination of both relative and absolute gas-phase basicities of amino acids and peptides has been reviewed by Harrison [18]; in $^{\circ}$ the ${ }^{\circ}$ present ${ }^{\circ}$ work, ${ }^{\circ}$ however, ${ }^{\circ}$ our ${ }^{\circ}$ concern $^{\circ}$ has ${ }^{\circ}$ been solely to achieve ranking. The following order for the gas phase basicities for peptides used in this study was therefore established: des-Arg ${ }^{1}$ bradykinin (PPGFSPFR) $>$ AFLDASR > AFLDASK > IGDYAGIK > leucineenkephalin (YGGFL).

Taken together with the energy-resolved CID data summarized above this suggests a correlation between gas-phase basicity and the difference in internal energy between $\mathrm{MH}^{+}$ions generated by AP-MALDI and electrospray. That is, for the most basic peptide studied, the applied resonance excitation voltage required to fragment $\mathrm{MH}^{+}$ions generated by electrospray exceeded that required to fragment equivalent AP-MALDI generated ions under identical instrumental conditions. The reverse was observed for a peptide incorporating no basic residues, while peptides of intermediate basicity showed little difference between the ionization methods. Close inspection of the data for the peptides of intermediate basicity studied shows smaller differences in the internal energies of ions generated by electrospray and AP-MALDI, which is in keeping with the overall trend.

It has been previously reported that the greater the difference in the gas-phase basicities between the matrix and the analyte in the MALDI experiment the greater the internal energy of the analyte ions produced; these conclusions were based on a study of the dissociation rate of a dinucleotide ion as a function of matrix ${ }^{\circ}$ basicity ${ }^{\circ}[8] .{ }^{\circ}$ The $^{\circ}$ results ${ }^{\circ}$ presented $^{\circ}{ }^{\circ}{ }^{\circ}{ }^{\circ}$ may $^{\circ}$ be explained in a similar manner, with the dependence of the internal energies of the analyte ions on their gas phase basicity being related to the importance of the proton transfer between matrix and analyte in the AP-MALDI experiment. These results, therefore, also suggest that the correlation noted here between peptide basicity and the difference in internal energies of $\mathrm{MH}^{+}$

Table 1. Applied resonance excitation voltage (peak-to-peak) necessary to achieve $50 \%$ fragmentation for $\mathrm{MH}^{+}$ions des-Arg ${ }^{1}$ bradykinin, AFLDASR, AFLDASK, IGDYAGIK and leucine-enkephalin, generated by both electrospray and AP-MALDI

\begin{tabular}{llcc}
\hline Peptide & $\begin{array}{c}\text { Ionization } \\
\text { technique }\end{array}$ & $\begin{array}{c}\text { Applied resonance excitation voltage } \\
\text { necessary to achieve 50\% } \\
\text { fragmentation (Volts }+/-0.01 \mathrm{~V})\end{array}$ & $\begin{array}{c}\text { Difference in applied resonance excitation } \\
\text { voltage necessary to achieve } 50 \% \\
\text { fragmentation }(\text { Volts) }\end{array}$ \\
\hline \hline des-Arg' ${ }^{1}$ bradykinin & ESI & 1.02 & $0.08(8.16 \%$ difference $)$ \\
AFLDASR & AP-MALDI & 0.94 & $0.01(0.99 \%$ difference $)$ \\
AFLDASK & ESI & 1.02 & $0.00(0.00 \%$ difference $)$ \\
IGDYAGIK & AP-MALDI & 1.01 & $-0.02(2.13 \%$ difference $)$ \\
Leucine-enkephalin & ESI & 0.96 & $-0.06(7.89 \%$ difference $)$ \\
\hline
\end{tabular}




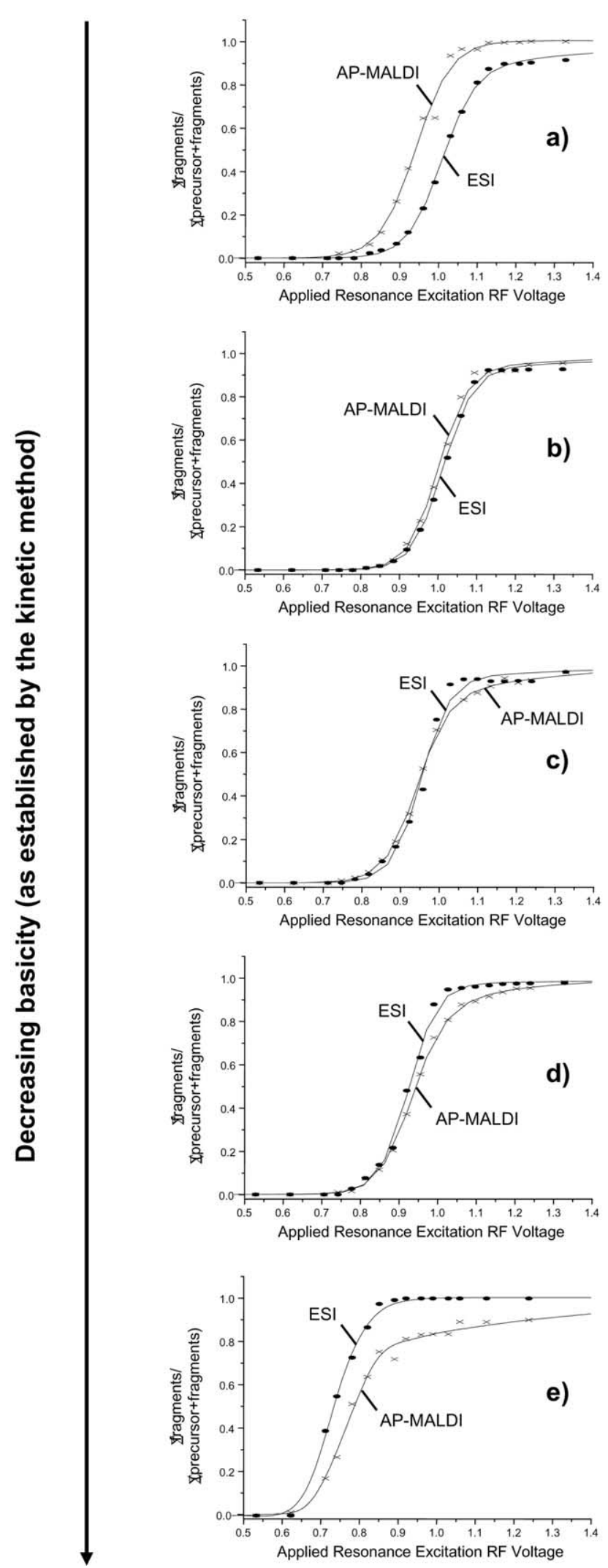

Figure 3. Fragmentation efficiency of $\mathrm{MH}^{+}$ions as a function of applied resonance excitation RF voltage for (a) des-Arg ${ }^{1}$-bradykinin, (b) AFLDASR, (c) AFLDASK, (d) IGDYAGIK, (e) leucineenkephalin, generated by electrospray and by AP-MALDI.

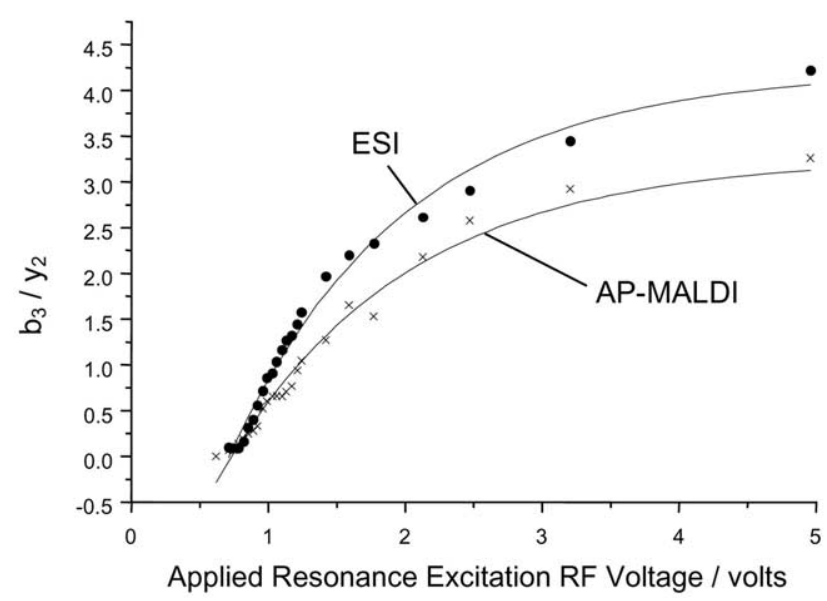

Figure 4. Ratio of $b_{3}: y_{2}$ first generation product ions of leucineenkephalin $\mathrm{MH}^{+}$ions generated by electrospray and by $\mathrm{AP}-$ MALDI as a function of applied resonance excitation RF voltage.

ions generated by AP-MALDI and electrospray is attributable primarily to a trend in the internal energies of the ions generated by AP-MALDI.

\section{Effect of Analyte Concentration on Internal Energy}

The demonstration in the above experiments of a dependence (for some peptide ions) of internal energy on the mechanisms of ionization has prompted us to investigate a possible relationship between fragmentation efficiency and analyte concentration, as it has been suggested that for techniques involving matrix assisted ionization there may be a correlation between analyte concentration and the internal energy of the analyte ions formed.

The relationship between peptide concentration and the extent of decomposition of $\mathrm{MH}^{+}$ions generated by electrospray and by AP-MALDI (when subjected to CID) was therefore investigated. The five peptides were used at three different concentrations $(5 \mathrm{pmol} / \mu \mathrm{l}, 500 \mathrm{fmol} / \mu \mathrm{l}$, and $50 \mathrm{fmol} / \mu \mathrm{l})$, and the extents of fragmentation of $\mathrm{MH}^{+}$ ions were measured as a function of the applied resonance excitation RF voltage (peak-to-peak). The results for the AP-MALDI generated ions demonstrate that, at identical applied resonance excitation RF voltages, the lower the concentration of the analyte the lesser the degree of fragmentation observed. This suggests that the analyte ions possess a lower internal energy when formed from lower concentration solutions. This trend was observed with all of the peptides examined, and is shown for des-Arg ${ }^{1}{ }^{\circ}$ bradykinin ${ }^{\circ}\left(\right.$ PPGFSPFR) ${ }^{\circ}$ Figure ${ }^{\circ}$ a). ${ }^{\circ}$ This ${ }^{\circ}$ reduction in analyte internal energy with decreasing analyte concentration in the AP-MALDI experiment may be explained as follows. As the analyte concentration is reduced there is a higher matrix:analyte ratio in the laser desorbed clusters. The dissociation of these desorbed clusters is an endothermic process and hence a greater reduction in analyte ion internal energy is observed for the more $^{\circ}$ dilute $^{\circ}$ clusters $^{\circ}\left[5,{ }^{\circ} 10\right] .{ }^{\circ}$ The ${ }^{\circ}$ equivalent ${ }^{\circ}$ experiments 

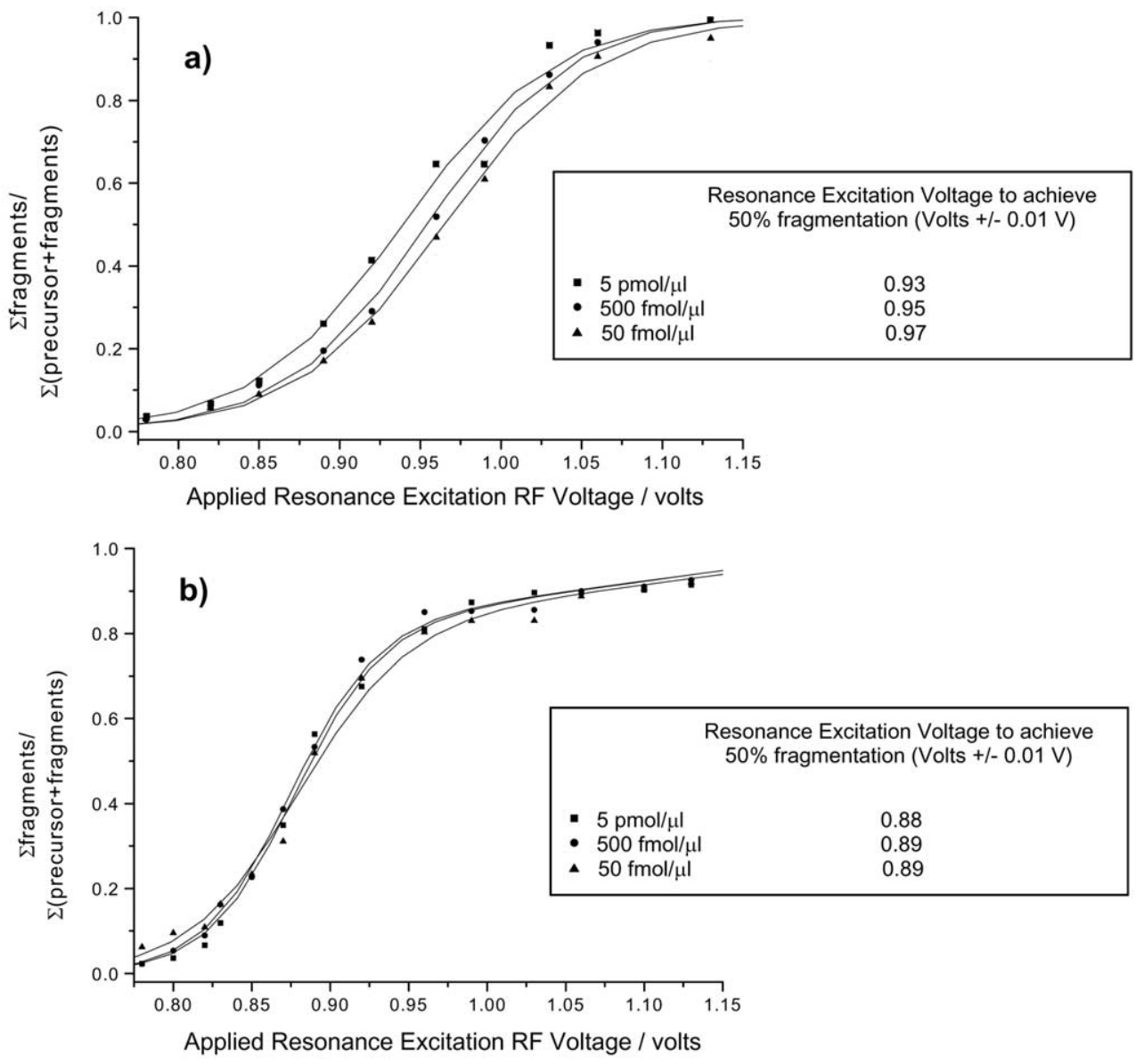

Figure 5. Fragmentation efficiency as a function of applied resonance excitation RF voltage for various concentrations of the $\mathrm{MH}^{+}$ion of des- $\mathrm{Arg}^{1}$ bradykinin (PPGFSPFR) generated by (a) AP-MALDI, (b) electrospray.

with electrospray-generated ions showed no correlation between analyte concentration and extent of fragmentation and is shown for des-Arg ${ }^{1}$ bradykinin (PPGFSPFR) in Figure $5 \mathrm{~b}$. $^{\circ}$ This $^{\circ}$ may $^{\circ}$ suggest $^{\circ}$ that ${ }^{\circ}$ during ${ }^{\circ}$ the ${ }^{\circ}$ electrospray process the excess of solvent molecules achieves equally effective analyte ion cooling across the range of concentrations examined.

\section{Effect of Ion "Cool Times" on Internal Energy}

The observation in the above experiments of differences in ion internal energy of some peptides depending on the mechanism and conditions of ion formation suggests that analysis using the ion trap does not allow equilibration of internal energy prior to the decomposition phase of the tandem MS experiment. In order to investigate this further, a series of time-resolved CID experiments were performed on the peptides leucineenkephalin ${ }^{\circ}$ and $^{\circ}{ }^{\circ} \operatorname{Ps}^{-} \operatorname{Arg}^{1{ }^{\circ}}$ bradykinin $^{\circ}$ (Figure ${ }^{\circ} 6 a^{\circ}{ }^{\circ}{ }^{\circ}{ }^{\circ} \mathrm{b}$, respectively). During these experiments the "cooling" period $^{\circ}$ before ${ }^{\circ}$ fragmentation ${ }^{\circ}\left(\text { period }^{\circ} 4^{\circ} \text { in }^{\circ} \text { Figure }^{\circ} 1\right)^{\circ}$ was varied through the use of customized waveforms which replaced the standard LCQ "DECA" waveforms (as described earlier).
These data (from the time-resolved analyses) are consistent with the equivalent data from the energyresolved $^{\circ}$ analyses $^{\circ}\left(\text { Figure }^{\circ} 3\right)^{\circ}$ in $^{\circ}$ term ${ }^{\circ}$ of ${ }^{\circ}$ the ${ }^{\circ}$ observed differences in the extents of fragmentation (and therefore by inference the internal energies) despite the standard LCQ "DECA" waveforms having been replaced with customized waveforms as described above.

It was also observed that, as the "cooling times" were increased, the extent of fragmentation observed for a fixed applied resonance excitation RF voltage initially increased quite rapidly (for about $100 \mathrm{~ms}$ ) before falling more slowly (for up to about $350 \mathrm{~ms}$ after they have peaked) until the ions reach internal energy equilibrium (Figure $\left.{ }^{\circ} 6\right)^{\circ}{ }^{\circ}$ These ${ }^{\circ}$ observations ${ }^{\circ}$ imply $^{\circ}$ that ${ }^{\circ}$ the ${ }^{\circ}$ internal energies of the ions initially undergo a rapid increase before dropping away at a slower rate. These observations are in keeping with the suggestion that initially an ion's kinetic energy is quenched through collisions with the helium buffer gas and that much of this quenched kinetic energy is redistributed as internal energy within the ion, thus the internal energy of the ion rises initially [11]. ${ }^{\circ}$ Quenching ${ }^{\circ}$ of $^{\circ}$ the ${ }^{\circ}$ internal ${ }^{\circ}$ energy $^{\circ}\left(\right.$ mainly $^{\circ}$ vibrational) is much less efficient and therefore occurs over longer ${ }^{\circ}$ time-scales ${ }^{\circ}\left(a^{\circ} \text { factor }{ }^{\circ} \text { of }^{\circ} \sim 10^{2^{\circ}} \text { longer }\right)^{\circ}[11] .{ }^{\circ} \mathrm{How}-$ 

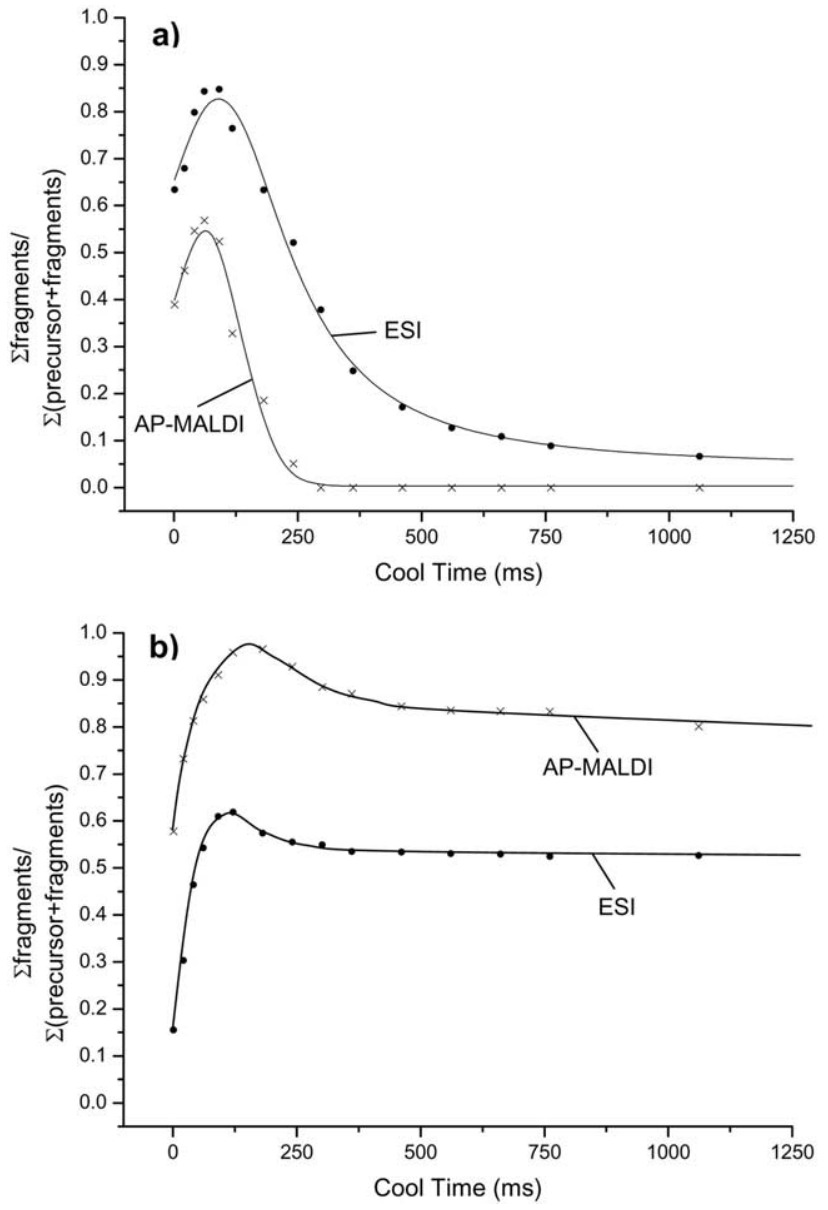

Figure 6. Fragmentation efficiency as a function of cooling period for (a) leucine-enkephalin $\mathrm{MH}^{+}$ions generated by electrospray and AP-MALDI with an applied resonance excitation RF voltage of $0.76 \mathrm{~V}$, (b) des- $\mathrm{Arg}^{1}$-bradykinin $\mathrm{MH}^{+}$ions generated by electrospray and AP-MALDI with an applied resonance excitation $\mathrm{RF}$ voltage of $0.97 \mathrm{~V}$.

ever, these time-scales for the collisional cooling of ion internal energy do not agree with those observed by Danell ${ }^{\circ}$ and $^{\circ} \mathrm{Glish}^{\circ}[1]^{\circ}$, who $^{\circ}$ observed $^{\circ}$ that ${ }^{\circ}$ the ${ }^{\circ}$ boundary activated decomposition onsets of leucine-enkephalin ions formed by nanoflow electrospray did not vary with the collisional cooling period prior to dissociation, and therefore concluded that the ions are collisionally cooled within a few milliseconds. This apparent discrepancy in collisional cooling time-scales is likely to be attributable in part to the different ionization techniques used (resulting in ion populations of different internal and kinetic energies as discussed above), and partly because of the different instruments used (source geometry and transfer lens voltages have both been shown ${ }^{\circ}$ to $^{\circ}$ effect $^{\circ}$ internal ${ }^{\circ}$ energy $\left.^{\circ}[19]\right) .{ }^{\circ}{ }^{\circ} t^{\circ} s^{\circ}$ also ${ }^{\circ}$ possible that the discrepancy may be due in part to the different techniques used to gauge internal energy. Glish and coworkers used the energies required for the onset of fragmentation to be observed, while here the energies required to achieve $50 \%$ fragmentation were used.

It was further observed in the present work that, even after these extended cooling times, equivalent ions formed by the two ionization techniques showed different propensities to fragment (and therefore by implication adopted different equilibrium internal energy distributions $)^{\circ}\left(\right.$ Figure $\left.^{\circ} 6\right) .{ }^{\circ}$ This $^{\circ}$ suggests $^{\circ}$ either ${ }^{\circ}$ that ${ }^{\circ}$ mo- $^{-}$ bile protons are located at different sites on the peptide ions generated by electrospray and AP-MALDI or that the two different ionization techniques produce ion populations differing in their three-dimensional structure. ${ }^{\circ}$ Danell ${ }^{\circ}$ and ${ }^{\circ} \mathrm{Glish}^{\circ}[1]^{\circ}$ and $^{\circ} \mathrm{Wysocki}^{\circ} \mathrm{and}^{\circ}$ coworkers $[2]^{\circ}$ investigated $^{\circ}$ the $^{\circ}$ differences $^{\circ}$ between ${ }^{\circ}$ the $e^{\circ}$ internal energies of $\mathrm{MH}^{+}$ions of leucine-enkephalin generated by liquid secondary ion mass spectrometry (LSIMS) and nanoflow electrospray, and LSIMS and electrospray, respectively, and both observed differences in the internal energies of ions generated by the two ionization techniques..$^{\circ}$ Danell ${ }^{\circ}$ and ${ }^{\circ}$ Glish $^{\circ}[1]^{\circ}$ derivatized ${ }^{\circ}$ leucineenkephalin at its $\mathrm{N}$-terminal in order to fix the charge location and still observed a difference in the internal energies of the ions formed by the two techniques, thus eliminating the possibility of the site of the charge location influencing ion internal energy. It is likely therefore that the two ionization techniques produce ion populations differing in their three-dimensional structure.

The differences in the rate of quenching of internal energy between the leucine-enkephalin and the des-Arg ${ }^{1}$ bradykininobserved in ${ }^{\circ}$ Figure $^{\circ} 6^{\circ}$ may $^{\circ}$ be attributed $^{\circ}$ in part to the greater number of internal modes that exist in des-Arg ${ }^{1}$ bradykinin (366 degrees of freedom) compared with leucine-enkephalin (219 degrees of freedom).

\section{Conclusions}

A series of experiments designed to assess the relationship between the mechanism and conditions of ionization and the apparent internal energy of the ions produced were performed. For the most basic peptide examined (as judged by ranking of gas-phase basicities using the kinetic method), des-Arg ${ }^{1}$ bradykinin, the extent of fragmentation of the $\mathrm{MH}^{+}$ion, at a given applied resonance excitation RF voltage (peak-to-peak), was greater for ions generated by AP-MALDI than by electrospray. The reverse was observed for a peptide incorporating no basic residues, (leucine-enkephalin). $\mathrm{MH}^{+}$ions derived from peptides of intermediate basicity showed little dependence of internal energy on the ionization method. The apparent dependence of internal energy on peptide basicity is likely to be attributable to the energetics of the proton transfer between analyte and matrix in the AP-MALDI process. Furthermore, the demonstration in the present work of a correlation between the extent of $\mathrm{MH}^{+}$ion fragmentation and the concentration of the analyte in the AP-MALDI process, but not the electrospray process, suggests that the matrix:analyte ratio in the analyte ion/matrix molecule laser desorbed clusters which undergo endothermic dissociation post-desorption, has a significant effect on analyte ion internal energy. Evidently, the excess of 
solvent present in the electrospray process achieves equally effective analyte ion cooling across the range of concentrations.

The dependence of the extent of fragmentation of peptide $\mathrm{MH}^{+}$ions on the mechanisms and conditions of ionization indicates differences in the internal energies of the trapped ion populations at the time of fragmentation. Time-resolved CID experiments demonstrated that the equilibration of internal energy, via collisions with buffer gas, is indeed slow on the timescale of the tandem MS experiment, requiring in excess of $250 \mathrm{~ms}$ to reach internal energy equilibrium.

Additionally, these analyses demonstrated that, even after these extended cooling times, equivalent ions formed by the two ionization techniques showed different propensities to fragment. These observations are consistent with the notion that the two ionization techniques produce ion populations differing in their threedimensional structure.

\section{Acknowledgments}

This work was funded by the Ministry of Defense and in part by the Defense Advanced Research Projects Agency (DARPA), Defense Science Office (DSO) under contract MDA972-00-C-0009.

SJG wishes to thank the Biotechnology and Biological Sciences Research Council for financial support under grant G17608.

\section{References}

1. Danell, A. S.; Glish, G. L. Evidence for Ionization-Related Conformational Differences of Peptide Ions in a Quadrupole Ion Trap. J. Am. Soc. Mass Spectrom. 2001, 12, 1331-1338.

2. Jones, J. L.; Dongre, A. R.; Somogyi, A.; Wysocki, V. H. Sequence Dependence of Peptide Fragmentation Efficiency Curves Determined by Electrospray Ionization/Surface-Induced Dissociation Mass Spectrometry. J. Am. Chem. Soc. 1994, 116, 8368-8369.

3. Cooks, R. G.; Busch, K. L. Matrix Effects, Internal Energies, and MS/MS Spectra of Molecular Ions Sputtered from Surfaces. Int. J. Mass Spectrom. Ion Processes 1983, 53, 111-124.

4. Cole, R. B.; Guenat, C. R.; Gaskell, S. J. Effect of Experimental Conditions on the Daughter Ion Spectra Derived from Tandem Mass Spectrometry of Steroid Glucuronides. Anal. Chem. 1987, 59, 1139-1144.

5. Karas, M.; Gluckmann, M.; Schafer, J. Ionization in MatrixAssisted Laser Desorption/Ionisation: Singly Charged Molecular Ions are the Lucky Survivors. J. Mass Spectrom. 2000, 35, $1-12$.
6. Gluckmann, M.; Karas, M. Perspective-The Initial Ion Velocity and Its Dependence on Matrix, Analyte, and Preparation Method in Ultraviolet Matrix-Assisted Laser Desorption Ionization. J. Mass Spectrom. 1999, 34, 467-477.

7. Gluckmann, M.; Pfenninger, A.; Kruger, R.; Thierolf, M.; Karas, M.; Horneffer, V.; Hillenkamp, F.; Strupat, K. Mechanisms in MALDI Analysis: Surface Interaction or Incorporation of Analytes? Int. J. Mass Spectrom. 2001, 210, 121-132.

8. Stevenson, E.; Breuker, K.; Zenobi, R. Internal Energies of Analyte Ions Generated from Different Matrix-Assisted Laser Desorption/Ionization Matrices. J. Mass Spectrom. 2000, 35, 1035-1041.

9. Michl, J. Secondary Ion Mass Spectrometry of Low-Temperature Solids. Int. J. Mass Spectrom. Ion Processes 1983, 53, 255-272.

10. Itina, T. E.; Zhigilei, L. V.; Garrison, B. J. Microscopic Mechanisms of Matrix Assisted Laser Desorption of Analyte Molecules: Insights from Molecular Dynamics Simulation. J. Phys. Chem. B. 2002, 106, 303-310.

11. Liere, P.; Steiner, V.; Jennings, K. R.; March, R. E.; Tabet, J. C. Influence of Ion Activation and Thermalization Effects on Reaction Rate Constants in a Quadrupole Ion Trap Mass Spectrometer. Int. J. Mass Spectrom. Ion Processes 1997, 167/168, 735-751.

12. Stafford, G. C., Jr.; Taylor, D. M.; Bradshaw, S. C.; Syka, J. E. P. Proceedings of the 35th ASMS Conference on Mass Spectrometry and Allied Topics; Denver, CO, May, 1987; p 775.

13. Kilby, G. W.; Sheil, M. M. Effect of Electrospray Ionization Conditions on Low-Energy Tandem Mass Spectra of Peptides. Org. Mass Spectrom. 1993, 28, 1417-1423.

14. Alexander, A. J.; Boyd, R. K. Experimental Investigations of Factors Controlling the Collision Induced Dissociation Spectra of Peptide Ions in a Tandem Hybrid Mass Spectrometer. I. Leucine Enkephalin. Int. J. Mass Spectrom. Ion Processes 1989, 90, 211-240.

15. Vachet, R. W.; Ray, K. L.; Glish, G. L. Origin of Product Ions in the MS/MS Spectra of Peptides in a Quadrupole Ion Trap. J. Am. Soc. Mass Spectrom. 1998, 9, 341-344.

16. Thibault, P.; Alexander, A. J.; Boyd, R. K.; Tomer, K. B. Delayed Dissociation Spectra of Survivor Ions from HighEnergy Collisional Activation. J. Am. Soc. Mass Spectrom. 1993, 4, 845-854.

17. McLuckey, S. A.; Cameron, D.; Cooks, R. G. Proton Affinities from Dissociations of Proton-Bound Dimers. J. Am. Chem. Soc. 1981, 103, 1313-1317.

18. Harrison, A. G. The Gas-Phase Basicities and Proton Affinities of Amino Acids and Peptides. Mass Spectrom. Rev. 1997, 16, 201-217.

19. Collette, C.; Drahos, L.; De Pauw, E.; Vekey, K. Comparison of the Internal Energy Distributions of Ions Produced by Different Electrospray Sources. Rapid Commun. Mass Spectrom. 1998, 12, 1673-1678. 